\title{
Presentación y valoración de los geoglifos del norte de Chile
}

Luis Briones $^{1}$ y Luis Alvarez ${ }^{2}$

\section{Introducción}

Al iniciar en 1982 las actividades académicas, de extensión y de investigación científica, la recientemente establecida Universidad de Tarapacá vigorizó y materializó en el extremo norte del país un programa con sendos proyectos sobre la importante e interesante temática antropológica que significan el conocimiento, la difusión y conservación de los geoglifos como patrimonio cultural autóctono.

Los geoglifos se definen como manifestaciones de arte rupestre de pueblos prehispánicos. En teoría, ellos pueden representar ideas sobre recursos naturales, centros ceremoniales, lugares de encuentro, tráfico comercial, rutas entre pueblos y poblados o simplemente ser demostraciones de comportamiento humano frente al medio ambiente en que ellos vivían.

\section{Antecedentes bibliográficos}

Las informaciones histórico-bibliográficas sobre geoglifos con énfasis de información cultural y científica datan desde 1905. En ese año Albert Plagemann, viajero alemán, en su obra Ueber die Chilenischen Pintados... describe y muestra fotografías de los geoglifos de Cerros Pintados; específicamente el panel que en recientes estudios hemos identificado con el no 12 y titulado "Hombres en fila".

En 1940, el geógrafo Carlos Keller en su trabajo el "Departamento de Arica" publica una interesante fotografía de los geoglifos del Cerro Sagrado de la Pampa Alto Ramírez en el valle de Azapa.

En 1943 el arqueólogo norteamericano Junius Bird, en su obra sobre el norte de Chile, se refiere al mismo tema de Keller. Los antropólogos Richard Schaedel

1 Instituto de Antropología, Universidad de Tarapacá, Arica, CHILE.

2 Departamento de Ciencias Sociales, Universidad de Tarapacá, Arica, CHILE. y Carlos Munizaga, por primera vez informan y grafican en su publicación, Arqueología Chilena. Contribución al estudio de la región comprendida entre Arica y La Serena (1957), los geoglifos del valle de Lluta, hoy día identificados como Panel no 8 "Hombres Grandes".

En 1975 los autores de este trabajo más los investigadores Percy Dauelsberg, Erie Vásquez y Sergio Chacón, en la Revista de la Universidad de Chile, Sede Arica $\mathrm{n}^{\circ} 3$ de ese año, escriben sobre "Los grandes geoglifos del valle de Lluta".

Posteriormente, el arqueólogo Lautaro Núñez en su obra Geoglifos y tráfico de caravanas en el desierto chileno (1976) cita varios yacimientos de esta región postulando interesantes planteamientos teóricos sobre su significado y representatividad.

En 1981 los arqueólogos Calogero Santoro e Iván Muñoz, en su informe de investigación arqueológica, publicado en Chungara 7: La aldea de cerro sombrero en el Período Desarrollo Regional de Arica y Patrón habitacional incaico del sector de Pampa Alto Ramírez en el valle de Azapa, también se refieren a este tema.

\section{Distribución geográfica}

Es interesante destacar el ámbito geográfico de dispersión de los geoglifos en territorio chileno. Se les encuentra en el área del río Loa por el sur y el valle de Lluta por el norte, en más de 15 sitios con sobre un millar de figuras de rico contenido plástico, dinámicas y de proporciones tales que en el momento tecnológico en que vivimos nos sorprenden por su factura y elaboración.

Llama la atención que los geoglifos de la mayor parte de los valles se ubican en los faldeos sur de la cadena de cerros que los encierran. También es notorio destacar que un gran número de sitios ubicados en la depresión intermedia, Pampa del Tamarugal, localiza sus geoglifos en los faldeos orientales de 
la cordillera de la Costa, expuestos hacia el oriente. Del mismo modo, en este vasto escenario, los geoglifos que están en la desembocadura de los valles y serranías del límite este de dicha pampa miran hacia occidente.

Por la cantidad de figuras geoglifos y temáticas que los componen, de norte a sur se destacan con sus caracteres de yacimientos los sitios: Lluta, Azapa, Camarones, Chiza, Suca, Tiliviche, Ex Aura o Abra, Altos de Pisagua, Cerro Unita, Tarapacá, Altos de Iquique, Santa Rosita en Pica, Guatacondo, Cerros Pintados, Quillagua, etc. (Figura 1).

\section{Estado de conservación}

El crítico estado de conservación de los geoglifos, calificados por las investigaciones preliminares, los mostró cubiertos o semicubiertos por capas de arena acarreada por la erosión eólica en algunos casos, y en otros, los litos de las figuras, rodados y dispersos por las pendientes debido a los sismos y a la acción de hombres y animales.

Considerando que los geoglifos son bienes culturales de innegable riqueza, la investigación se orientó al rescate de ellos mediante trabajos de conservación, en los sitios con acceso a caminos y carretera, teniendo como objetivos principales el crear conciencia por nuestro patrimonio cultural autóctono, incentivar el interés científico para su investigación, implementar el atractivo turístico de la región e ir a la recuperación científica de estos bienes.

\section{Técnicas de elaboración}

Estos originales diseños de representación cultural: zoomorfos, antropomorfos o de figuras geométricas, al ser procesados, analizados comparados y codificados permitió concluir y definir técnicas de elaboración. La mayoría de estas figuras están confeccionadas por la técnica de extracción, que consiste en extraer el material de superficie que cubren las figuras trazadas en los cerros del desierto. Este material que es desplazado enmarca y destaca a su vez un área de color claro, del geoglifo, que contrasta con el fondo natural gris oscuro. Los sitios más representativos de esta técnica son Cerros Pintados, Unita, Ex Aura, etc. (Figura 2). En los sitios Lluta, Azapa, Tiliviche, Chiza, Tarapacá, etc., la técnica es diferente. La denominamos como "técnica de adición", consistente en agregar o acumular piedras de color gris oscuro, para definir la figura del geoglifo, la que contrasta sobre un fondo claro característico (Figura 3).

También existe una técnica mixta, que es la suma de los dos procesos señalados anteriormente. Mediante la extracción definen un área o figura por adición, la complementan hacia un realismo original; tal es el caso de algunos de los geoglifos de Unita, Ex Aura y Cerros Pintados, específicamente así están definidas las figuras "felino" y "camélido moteado".

\section{La restauración y conservación}

El proceso de restauración y/o conservación de los geoglifos de la I Región comprometió diferentes fases con tratamientos metodológicos específicos:

1) Observación: Fichaje gráfico y fotográfico, estado de conservación.

2) Análisis: De técnicas, diseños, diagnóstico del tratamiento, etc.

3) Proceso: Ejecución de limpieza, consolidación, demarcación, etc.

4) Evaluación: Fichaje fotográfico, comparación.

5) Informe: Elaboración de informe final del proceso de la puesta en valor del bien cultural.

Siete son los yacimientos con geoglifos que han sido sometidos a procesos de restauración y/o conservación. Los trabajos se iniciaron en el valle de Lluta, en el año 1975, y concluyeron en los sitios Cerro Unita y Ex Aura o Abra, en 1982. Los antecedentes cuantitativos se resumen en la Tabla 1. Este resultado es el producto de las observaciones, análisis y clasificación de cada uno de los sitios trabajados y presentados en este informe. Se dedujeron de un estudio general que contempló los siguientes aspectos:

a) $\mathrm{N}^{\mathrm{o}}$ de paneles identificados a la fecha.

b) $\mathrm{N}^{\mathrm{o}}$ de figuras que se identifican en cada panel.

c) Censo de figuras de cada sitio en general.

d) Clasificación de figuras geométricas: círculos, rombos, cuadrados, cruces, etc. 


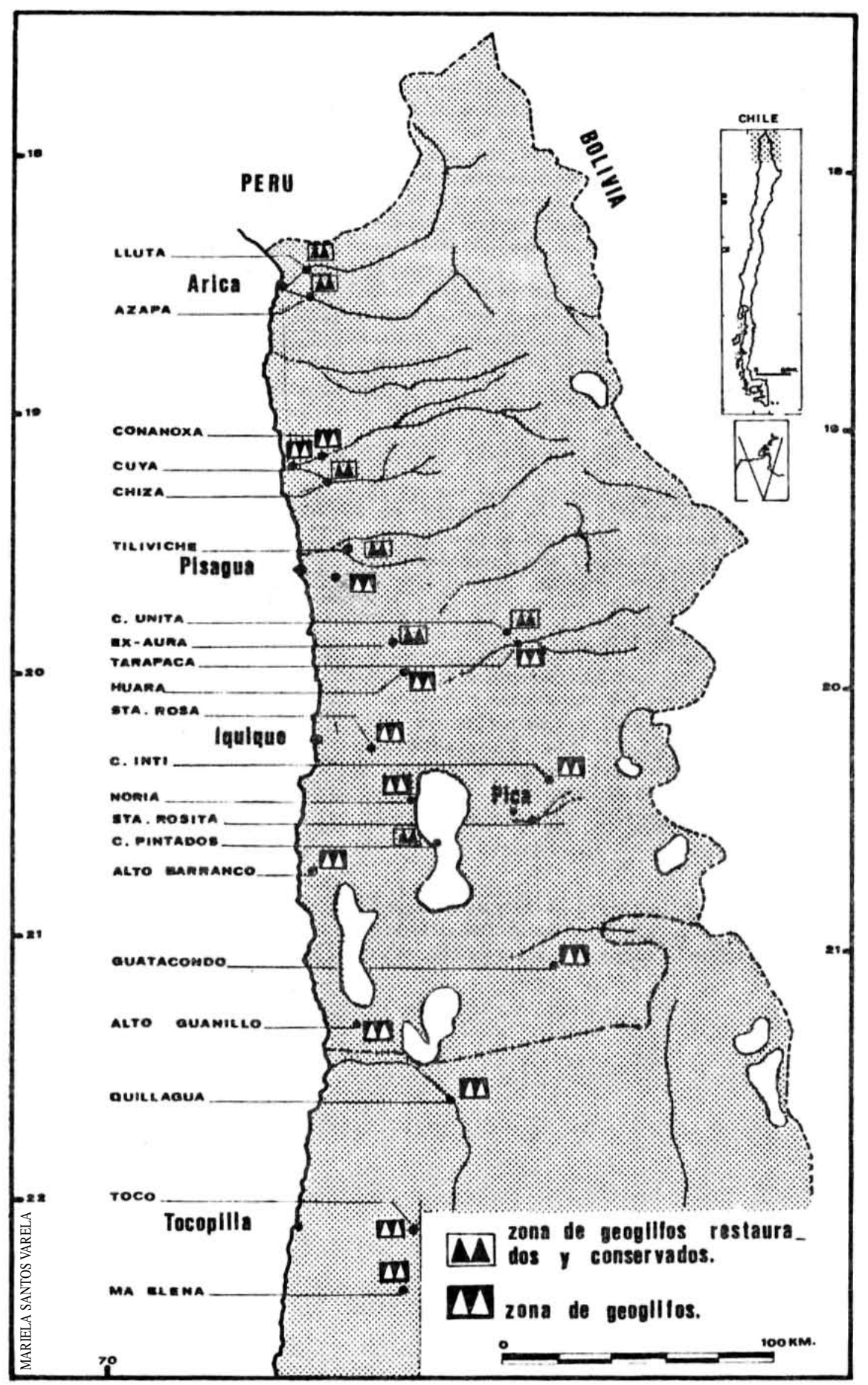

Figura 1. Ubicación geográfica de los geoglifos. 


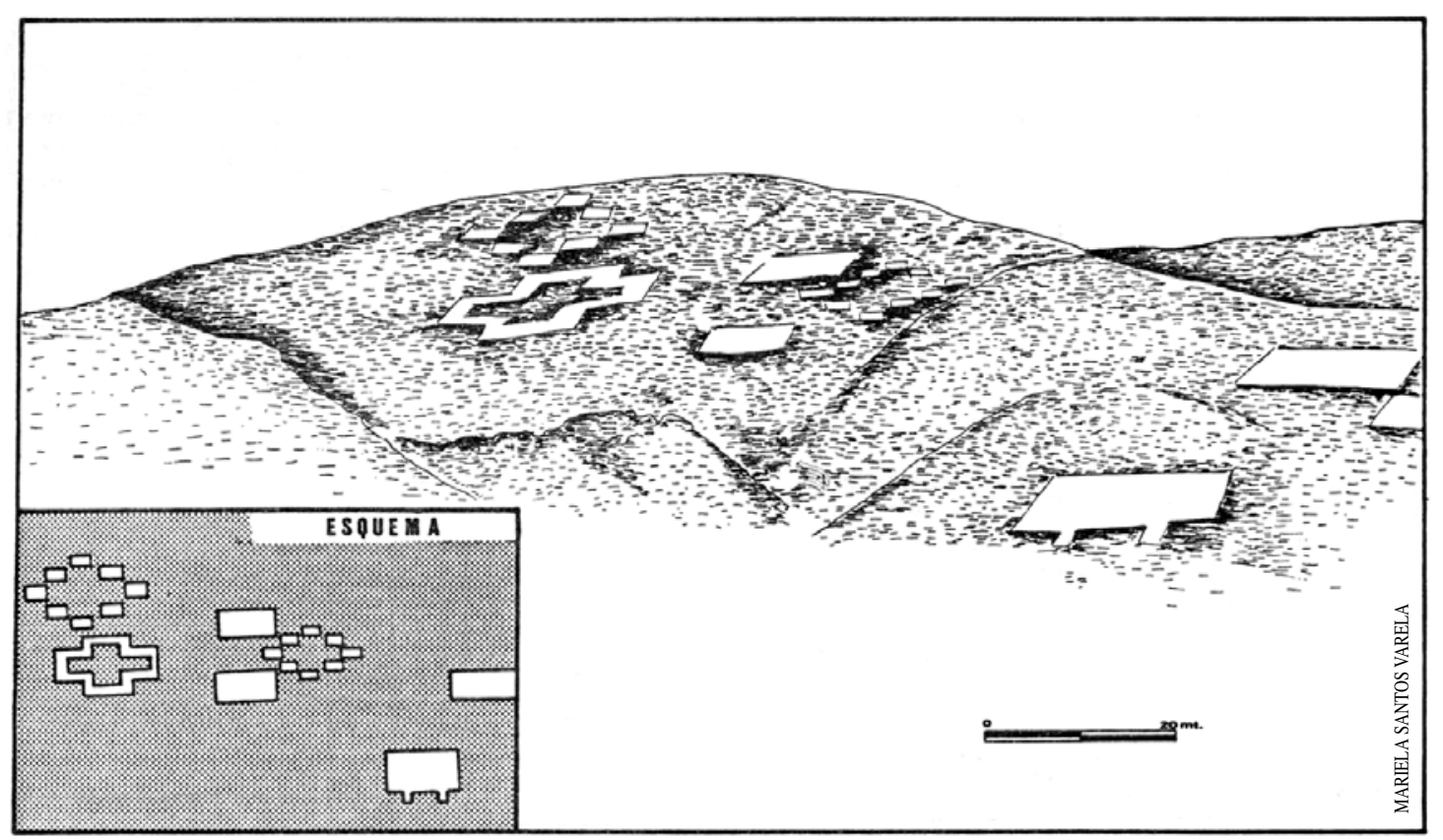

Figura 2. Cerro Pintados: Panel 40 "Gran cruz bajo gran rombo".

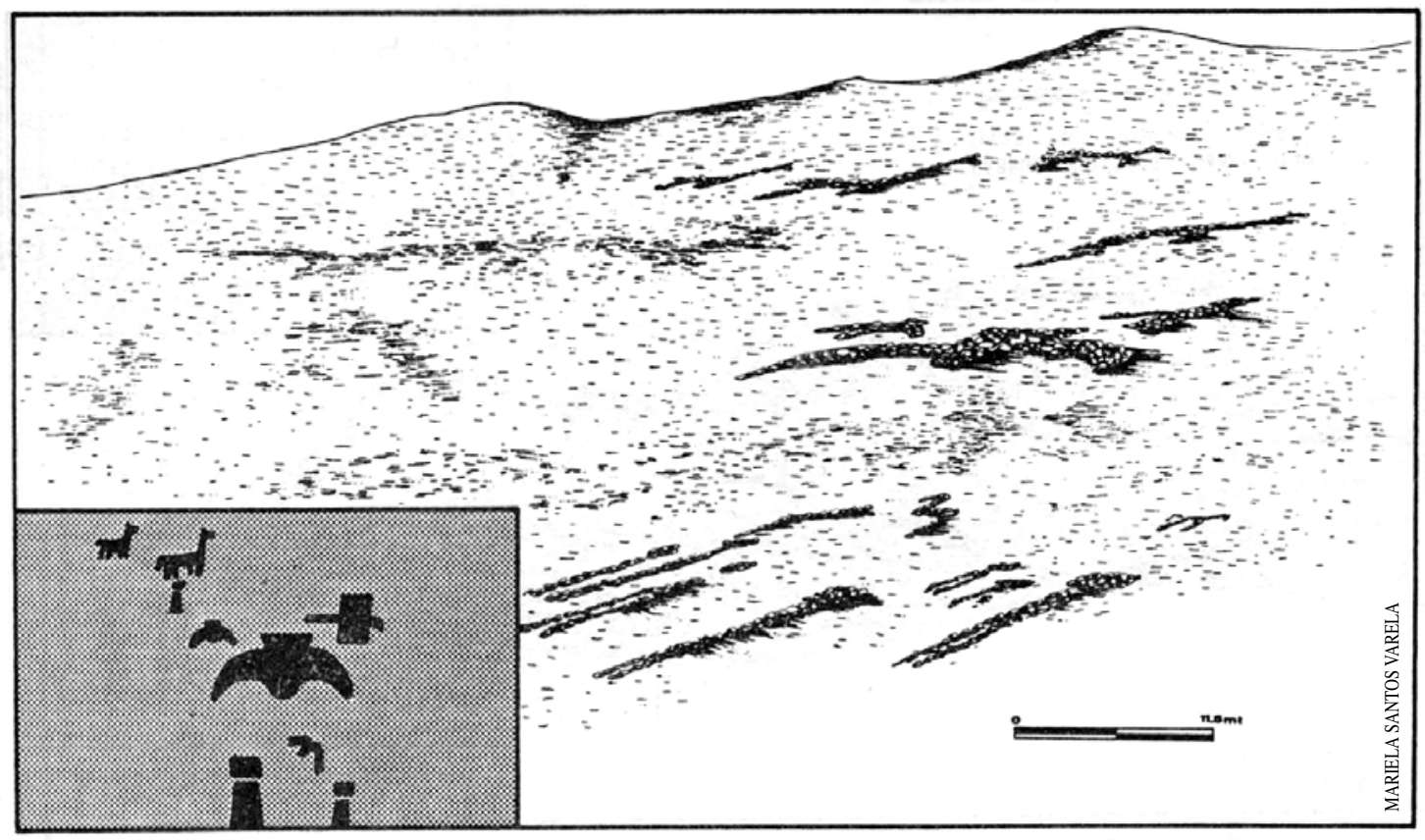

Figura 3. Lluta: Panel 4 "El águila". 


\begin{tabular}{|c|c|c|c|c|c|c|c|c|c|c|}
\hline $\begin{array}{l}\text { SITIOS ARQUEOLOGICOS } \\
\text { TRATADOS. }\end{array}$ & $\begin{array}{c}\text { No } \\
\text { PankELES }\end{array}$ & $\begin{array}{c}\text { no } \\
\text { FIGURAs }\end{array}$ & $\begin{array}{l}\text { * fligs } \\
\text { ANTROP. }\end{array}$ & $\begin{array}{l}x \text { fllas } \\
\text { zoom. }\end{array}$ & $\begin{array}{l}\text { Xfles. } \\
\text { GeOM. }\end{array}$ & TEGNICAS & ConseRv. & REST. & $\begin{array}{l}x \\
\text { TESTIEOS }\end{array}$ & $\begin{array}{l}\text { SUP. ESTIMADA } \\
\text { TOTAL. TRATADA }\end{array}$ \\
\hline LLUTA & 18 & 131 & 60 & 40 & - & aditiva & 50 & 20 & 30 & $32.000 \mathrm{~m}^{2}$ \\
\hline AZAPA & 10 & 70 & 17 & 73 & - & $\begin{array}{l}\text { extractiva } \\
\text { aditiva }\end{array}$ & 50 & 30 & 20 & $20.000 \mathrm{~m}^{2}$ \\
\hline CHIZA & 5 & 52 & 55 & 30 & 15 & $\begin{array}{l}\text { extractiva } \\
\text { aditiva }\end{array}$ & 60 & 20 & 20 & $7000 \mathrm{~m}^{2}$ \\
\hline TILIVICHE & 1 & 74 & 5 & 95 & - & aditiva & 75 & 5 & 20 & $13.000 \mathrm{~m}^{2}$ \\
\hline EX-AURA & 5 & 45 & 50 & 30 & 20 & $\begin{array}{l}\text { extractiva } \\
\text { aditiva } \\
\text { mixta }\end{array}$ & 60 & 10 & 30 & $20.000 \mathrm{~m}^{2}$ \\
\hline UNITA & 2 & 15 & 7 & - & 93 & $\begin{array}{l}\text { extractiva } \\
\text { aditiva } \\
\text { mixta }\end{array}$ & 70 & 10 & 20 & $12.000 \mathrm{~m}^{2}$ \\
\hline C. PINTADOS & 60 & 450 & 25 & 25 & 50 & $\begin{array}{c}\text { extractiva } \\
\text { mixta }\end{array}$ & 60 & 20 & 20 & $50.000 \mathrm{~m}^{2}$ \\
\hline totales & 101 & 837 & 31.3 & 42 & 25.4 & - & 60.7 & 16.4 & 22.9 & $154.000 \mathrm{~m}^{2}$ \\
\hline
\end{tabular}

Tabla 1. Información estadística sobre los geoglifos tratados.

e) Clasificación de figuras zoomorfas: camélidos, felinos, aves, peces y otros.

f) Figuras antropomorfas: Hombres en actitudes dinámicas participando en rituales, o simplemente manifestando presencia o poder.

g) Superficie que ocupa cada uno de los geoglifos. Se consideró no solo el espacio ocupado por el diseño sino que toda la superficie que la compromete, es decir, su entorno inmediato.

h) Grado de "limpieza" a que fue sometida la figura durante el proceso de recuperación.

i) Grado de "restauración" a que se debió someter el geoglifo según el diagnóstico.

j) Porcentaje de "pérdida", estimado de las figuras erosionadas o destruidas total o parcialmente, por diferentes causales. Pérdida que en la gran mayoría de los casos se tornó irrecuperable en el momento de los trabajos.

k) Porcentaje de “testigos". Establecido según diagnósticos previos, ya que es importante determinar y precisar en un modelo de restauración cuáles son los motivos originales del monumento con el propósito de tenerlo como testimonio y antecedente comparativo en relación a lo corregido o "recuperado".
1) "Tamaño" de las figuras observadas, medidas y comparadas; así por ejemplo: el tamaño 1 ("pequeños") clasifica aquellas superficies de hasta $100 \mathrm{~m}^{2}$; tamaño 2 ("regulares") considera superficies de hasta $400 \mathrm{~m}^{2}$; tamaño 3 ("grandes"), con superficies de hasta $1000 \mathrm{~m}^{2}$ y tamaño 4 ("gigantes"), con geoglifos que cubren zonas de hasta $2500 \mathrm{~m}^{2}$.

m) Posición del panel y su orientación.

El análisis cualitativo y cuantitativo de los elementos codificados en los sitios de geoglifos investigados y trabajados aportó antecedentes valiosos para la definición de patrones estilísticos y sus posibles difusiones e influencias. El área de geoglifos de Lluta y Azapa permitió definir un estilo tipificado por la figura humana; y el sitio Cerro Pintados, el estilo Cerro Pintados tipificado por su principal elemento antropomorfo, con variantes hacia otras formas como el "rombo escalerado" y "camélido moteado".

El sitio de mayor significación cuantitativa sin lugar a dudas es Cerro Pintados, con un total de 450 figuras si se considera el total de 837 inventariadas en los sitios procesados (ver Tabla 1).

En $154.000 \mathrm{~m}^{2}$ se estima la superficie que fue sometida de alguna manera a procesamiento; de ella el $60.7 \%$ corresponde a limpieza; a restauración 
el $16.4 \%$; y a testigos el $22.9 \%$. Es importante destacar el alto porcentaje sometido a proceso de limpieza (60.7\%), ello significa la no alteración de los diseños originales, garantizándose así su conservación y autenticidad. Del mismo modo, el $22.9 \%$ de superficies o figuras que se mantienen como "testigos" e inalteradas, son un índice claro del respeto y cuidado que se debe tener en consideración con estos bienes culturales, ya que son recuperables en un alto porcentaje. El 16.4\% de los geoglifos sometidos a restauración es un índice muy bajo de tratamiento para este tipo de expresiones, considerando sus largos períodos de exposición a la intemperie, sujetos a cambios climáticos, erosión por fenómenos naturales y deterioro causado directa o indirectamente por el hombre.

\section{Conclusiones}

La investigación realizada en una parcialidad de los yacimientos de geoglifos tratados en el norte de Chile que en este trabajo se exponen es el inicio sistemático de un programa acorde con las políticas de desarrollo de la investigación regional y nacional que identifica a la Universidad de Tarapacá.

Estamos conscientes de que la presente información no será suficiente para satisfacer numerosas inquietudes de investigadores y estudiosos en torno a los geoglifos para responder las interrogantes que su complejidad encierran: ¿Cuáles son sus orígenes, su funcionalidad, qué representan, a qué momento cultural pertenecen?, etc. Del mismo modo postular sobre la existencia de algún centro de dispersión, área de difusión, estilos, aplicación de técnicas, asociación de elementos decorativos con algunos rasgos peculiares de los diferentes momentos culturales prehispánicos de la región, etc.

Al concluir este trabajo expresamos que se presenta con la intención de aportar nuevas facetas al estudio del arte rupestre en Chile y contribuir al enriquecimiento de la información para una mejor comprensión de la prehistoria nacional.

\section{REFERENCIAS CITADAS}

ALVAREZ, L. y L. BRIONES y otros, 1978. Grandes geoglifos del valle de Lluta. Revista Universidad de Chile, Arica.

BIRD, J., 1943. Excavations in Northern Chile. Anthropological Papers of the American Museum of the Natural History. XXXVIII part. IV. Nueva York.

BRIONES, L., 1979. Arte rupestre andino: Geoglifos del norte de Chile. Actas del III Congreso del Hombre y la Cultura Andina, vol. 2. Lima.

MUÑOZ, I., 1981. La aldea de Cerro Sombrero en el Período del Desarrollo Regional de Arica. Chungara 7.
NUÑEZ, L., 1976. Geoglifos y tráfico de caravanas en el desierto chileno. En Homenaje al Dr. Gustavo Le Paige s. $j$. Universidad del Norte, Antofagasta.

PLAGEMANN, A., 1906. Ueber die Chilenischen Pintados... XIV Congreso Internacional de Americanistas, Stuttgart.

REICHE, M., 1958. Secreto de la pampa. Nazca-Perú. Lima.

SANTORO, C. e I. MUÑOZ, 1981. Patrón habitacional incaico en el área de Alto Ramírez. Chungara 7.

SCHAEDEL, R., 1957. Arqueología chilena. Contribución al estudio de la región comprendida entre Arica y La Serena. Universidad de Chile, Santiago. 